\title{
A Wideband Hybrid Fractal Ring Antenna for WLAN Applications
}

\author{
Atif Jamil $\triangle{ }^{1}$ Muhammad Rauf $\mathbb{D}^{1}{ }^{1}$ Abdul Sami $\mathbb{D},{ }^{1}$ Arsalan Ansari $\mathbb{D},{ }^{1}$ \\ and Muhammad Dawood Idrees ${ }^{2}{ }^{2}$ \\ ${ }^{1}$ Department of Electronic Engineering, Dawood University of Engineering \& Technology Karachi, M. A Jinnah Road, \\ Karachi-74800, Pakistan \\ ${ }^{2}$ Department of Industrial Engineering and Management, Dawood University of Engineering \& Technology Karachi, \\ M. A Jinnah Road, Karachi-74800, Pakistan \\ Correspondence should be addressed to Atif Jamil; atif.jamil@duet.edu.pk
}

Received 17 September 2021; Revised 3 January 2022; Accepted 8 January 2022; Published 21 February 2022

Academic Editor: Muhammad Inam Abbasi

Copyright (c) 2022 Atif Jamil et al. This is an open access article distributed under the Creative Commons Attribution License, which permits unrestricted use, distribution, and reproduction in any medium, provided the original work is properly cited.

\begin{abstract}
We propose the design of a novel fractal antenna that is both unique and performance-driven. Two important antenna design features, miniaturization and wideband operation, are combined in this work. A ring-shaped antenna is designed using the wellknown fractal geometry. This hybrid geometry is a fusion of meander and Koch curve shapes. The geometrical construction of the proposed antenna is compared to the standard Koch curve geometry. It is shown that combining the meander and Koch curve shapes increases the effective electrical length. The wider bandwidth is achieved by bringing the higher modes together. The overall dimensions of proposed meander Koch curve fractal ring antenna are $45 \times 25 \times 1.6 \mathrm{~mm}^{3}$. The resonance frequency of the antenna is between 4.94 and $6.12 \mathrm{GHz}(\% \mathrm{BW}=21.83$ ), which covers the entire $5 \mathrm{GHz}$ WLAN band. The prototype has been fabricated and experimentally verified.
\end{abstract}

\section{Introduction}

The advancement of wireless communication technology has raised the bar for modern living. The sophisticated devices have brought a great degree of freedom to the conventional stationary working styles. The demand for data-hungry applications and multimedia streaming videos has given rise to the improved quality of service (QoS) in wireless communication systems. Antenna, an essential part of wireless communication system, must respond to the call of QoS improvement by enhancing its performance by aiming wide bandwidth, high gain, reduced return loss, omnidirectional radiation pattern, low cross-polarization, and reduced cost for fabrication. Fractal geometry has a long history; since its inception, fractals have been practically deployed in various technical fields. Mandelbrot introduced the term fractal from the Latin word "Fractus" in $1975[1,2]$. Fractals shapes are nowhere differentiable as they are resultant of a recursive process. The increased bandwidth has been linked to fractal geometry's self-similar, convoluted and jagged structures. Additionally, fractal geometry is used in antennas because of its unique properties, including small size and multiband/wideband behavior [3]. Numerous researchers have advocated incorporating fractal geometry into their antenna research. Several antenna geometries have been examined, including Koch, Cantor, Sierpinski, fractal tree, and Minkowski. In [4], an octagonal Fractal microstrip patch antenna with a superwideband bandwidth range of $10 \mathrm{GHz}-50 \mathrm{GHz}$ has been presented. For numerous applications such as PCS, WLAN, WiFi, WiMax, and other communication systems, a Koch-like fractal curve has been proposed [5]. A Pythagorean tree was placed in a T-patch to form an ultrawideband (UWB) antenna [6]. Grounded coplanar waveguides have been used to enhance the bandwidth of conventional Sierpinski carpet antenna [7]. Additionally, various fractal shapes have been used to improve the properties of the dielectric resonator antennas [8-13].

Numerous fractal geometries have been combined to enhance the properties of fractal antennas such as 
multiband/wideband operation and size reduction. Using Koch curves as inductive loading and Sierpinski carpet as a slot loading, the resonant frequency and the size of a patch antenna can be reduced, as shown by experiments in [14]. Fractal shapes have been modified to alter the characteristics of the antenna which are driven by the shape of antenna. A perturbed Sierpinski fractal antenna with slotted ground plane has been proposed for GSM/DCS/ PCS/IMT-2000/ISM/satellite DMB bands [15]. For a WLAN USB dongle, the hybrid meander-Koch monopole antenna was presented in [16]. The antenna is multibandcapable, operating throughout the whole IEEE $802.11 \mathrm{a} / \mathrm{b} / \mathrm{g}$ spectrum. In [17], a UWB antenna based on Giuseppe Peano and Sierpinski carpet fractal geometries was proposed. Two different fractal antennas have been fused together to design a multiband antenna for Wi-Max and C-band applications [18]. A multiband hybrid fractal antenna based on Koch-Minkowski geometry has been developed for use in a variety of wireless applications [19]. A report on the construction of a hybrid fractal antenna comprising Giuseppe Peano, Cantor set, and Sierpinski carpet for industrial, scientific, and medical (ISM) band has been presented in [20]. A hybrid fractal antenna based on Moore, Minkowski, and Koch curve for multiband applications such as Wi-Fi, Bluetooth, and Wi-MAX has been reported in [21]. A hybrid fractal antenna with a defected ground structure (DGS) was optimized for $S, C$, and $X$ applications using artificial neural networks (ANNs) [22]. An ultrawideband hybrid fractal antenna based on Koch and Sierpinski Fractals has been reported in [23]. Using the well-known Minkowski and Hilbert curves, a hybrid fractal antenna has been designed [24].

In this paper a hybrid Fractal antenna geometry has been proposed for $5 \mathrm{GHz}$ WLAN band. The antenna has been constructed by merging the meander and Koch curve geometries. The antenna has been experimentally studied to optimize its performance impedance bandwidth. The proposed antenna has been designed to operate in the IEEE 802.11a (WLAN) i.e., 5.15-5.825 band. The antenna prototype has been physically analysed and the actual measurement results have been found to be in good agreement with the simulation results. The simulation and measurement results indicate that the proposed antenna can achieve an impedance bandwidth of more than $1 \mathrm{GHz}$ at $-10 \mathrm{~dB}$ scale. The configuration of the proposed antenna has been described in Section 2. Section 3 presents a study on the parametric optimization of the proposed meanderKoch Fractal ring antenna. Experimental results have been presented in Section 4. The conclusion follows in Section 5.

\section{Antenna Design}

Figure 1 illustrates the suggested antenna design. The hybrid meander-Koch Fractal ring antenna measures $45 \times 25 \mathrm{~mm}^{2}$ in total and is printed on top of FR-4 dielectric substrate. The dielectric substrate has a height of $h=1.6 \mathrm{~mm}$ and a relative dielectric constant of $\varepsilon_{r}=4.34$. The antenna is fed with a

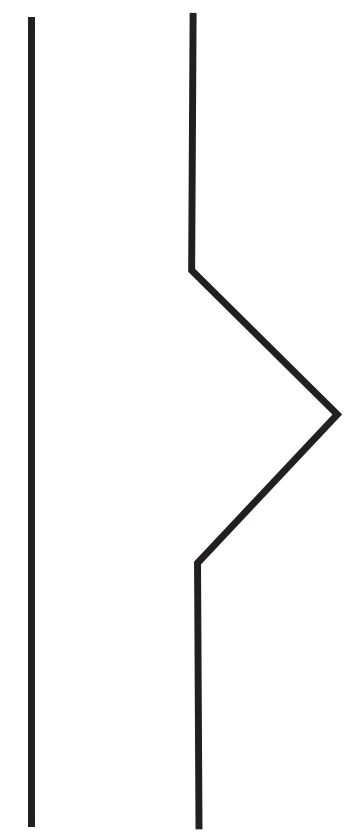

(a) (b)

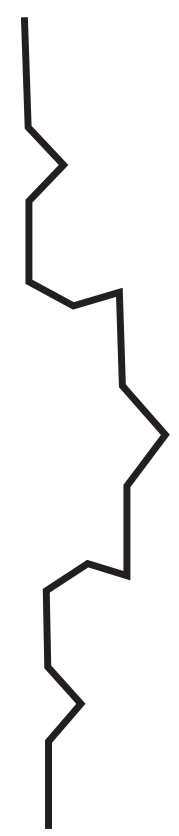

(c)
FIgURE 1: Generation of a standard Koch curve geometry. (a) First iteration, (b) second iteration, (c) third iteration.

microstrip transmission line terminated with a $50 \Omega$ feeder. The proposed antenna has a ground plane on the opposite side of the radiating hybrid meander-Koch Fractal ring element.

The construction of the hybrid meander-Koch Fractal ring antenna is defined by using the iteration function system (IFS) algorithm [25-30]. To justify the complex design and construction of a new Fractal shape, the proposed hybrid meander-Koch Fractal antenna's generator is compared to that of a standard Koch curve Fractal antenna. The shapes are compared according to their ability to increase the effective electrical length.

2.1. Construction of Standard Koch Curve Using IFS. Helge von Koch, a Swedish mathematician, invented the standard Koch curve geometry in 1904 [28]. The standard Koch is constructed using the initiator-generator method. As illustrated in Figures 1(a)-1(c), this method applies several transformations to a straight line in order to convert it to a Koch shape. A straight line (initiator) is divided into three equal sections, with the middle section further subdivided into two equal sections. The resultant shape is called the generator, and this procedure can be repeated to achieve the higher iterations.

The IFS algorithm is used to construct the standard Koch curve shown in Figures 1(a)-1(c). The IFS is formed by the set of affine transformations to generate the standard Koch. In its construction, it is assumed that a straight line of unit length is placed along the $x$-axis with its left end placed at the origin. The transformations used to construct the Koch curve antenna's generator are as follows: 


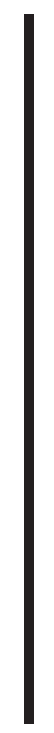

(a)

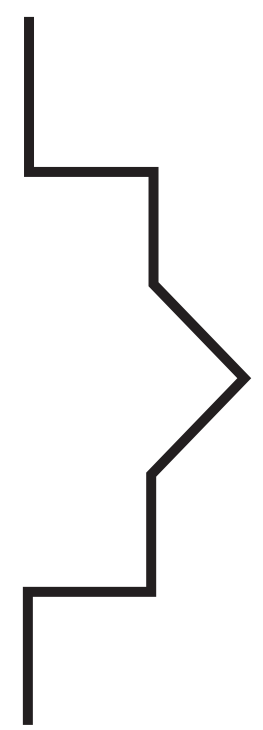

(b)

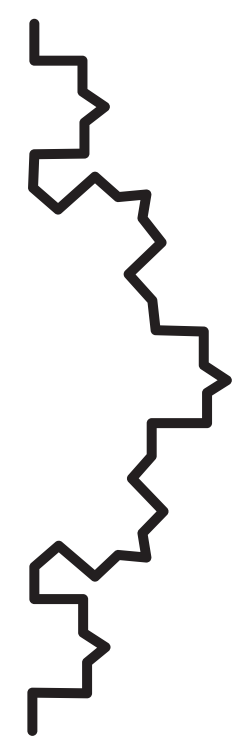

(c)
FIgURE 2: Transformations of the hybrid meander-Koch curve Fractal antenna. (a) $0^{\text {th }}$ transformation. (b) $1^{\text {st }}$ transformation. (c) $2^{\text {nd }}$ transformation.

$$
\begin{aligned}
& W_{1}\left(\begin{array}{l}
x^{\prime} \\
y^{\prime}
\end{array}\right)=\left[\begin{array}{ll}
\frac{1}{3} & 0 \\
0 & \frac{1}{3}
\end{array}\right]\left(\begin{array}{l}
x \\
y
\end{array}\right), \\
& W_{2}\left(\begin{array}{l}
x^{\prime} \\
y^{\prime}
\end{array}\right)=\left[\begin{array}{ll}
\frac{1}{3} \cos 60^{\circ}-\frac{1}{3} \cos 60^{\circ} \\
\frac{1}{3} \sin 60^{\circ} & \frac{1}{3} \cos 60^{\circ}
\end{array}\right]\left(\begin{array}{l}
x \\
y
\end{array}\right)+\left(\begin{array}{l}
\frac{1}{3} \\
0
\end{array}\right) \text {, } \\
& W_{3}\left(\begin{array}{l}
x^{\prime} \\
y^{\prime}
\end{array}\right)=\left[\begin{array}{cc}
\frac{1}{3} \cos 60^{\circ} & -\frac{1}{3} \sin 60^{\circ} \\
-\frac{1}{3} \sin 60^{\circ} & \frac{1}{3} \cos 60^{\circ}
\end{array}\right]\left(\begin{array}{l}
x \\
y
\end{array}\right)+\left(\begin{array}{c}
\frac{1}{2} \\
\frac{1}{2} \sin 60^{\circ}
\end{array}\right) \text {, } \\
& W_{4}\left(\begin{array}{l}
x^{\prime} \\
y^{\prime}
\end{array}\right)=\left[\begin{array}{ll}
\frac{1}{3} & 0 \\
0 & \frac{1}{3}
\end{array}\right]\left(\begin{array}{l}
x \\
y
\end{array}\right)+\left(\begin{array}{c}
\frac{2}{3} \\
0
\end{array}\right) \text {. }
\end{aligned}
$$

The generator is obtained by combining the segments as

$$
A_{1}=W(A)=W_{1}(A) \cup W_{2}(A) \cup W_{3}(A) \cup W_{4}(A) .
$$

The procedure described previously can be used to generate iterations of higher order. To generate self-similar geometry, the distance between the start and end points of all iterations must be the same. The dimensions of self-similarity are calculated as

$$
D=\frac{\log 4}{\log 3}=1.2618
$$

This implies that four identical copies are scaled by a factor of three during each iteration.
2.2. Construction of Hybrid Meander-Koch Curve Using IFS. Hybrid fractal geometries are created by fusing two fractal geometries together or by fusing a fractal shape with a nonfractal shape. Additionally, certain hybrid fractal shapes can be created by combining multiple shapes. As illustrated in Figures 2(a)-2(c), the hybrid meander-Koch curve generator is created by combining the meander and Koch curve shapes. The meander and Koch curve generators (first iteration) each contain four and five segments, respectively. However, as illustrated in Figure 2(b), when the two shapes are combined, the resulting generator contain eight segments. This method clearly contributes to antenna's size reduction by increasing the effective electric length. The IFS algorithm for constructing the segments of the meanderKoch curve fractal antenna is as follows:

$$
\begin{aligned}
& W_{1}\left[\begin{array}{l}
x \prime \\
y^{\prime}
\end{array}\right]=\left[\begin{array}{cc}
\frac{1}{5} & 0 \\
0 & \frac{1}{5}
\end{array}\right]\left[\begin{array}{l}
x \\
y
\end{array}\right] \\
& W_{2}\left[\begin{array}{l}
x \prime \\
y \prime
\end{array}\right]=\left[\begin{array}{cc}
0 & -\frac{1}{5} \\
\frac{1}{5} & 0
\end{array}\right]\left[\begin{array}{l}
x \\
y
\end{array}\right]+\left[\begin{array}{l}
\frac{1}{5} \\
0
\end{array}\right] \text {, } \\
& W_{3}\left[\begin{array}{l}
x \prime \\
y^{\prime}
\end{array}\right]=\left[\begin{array}{ll}
\frac{1}{5} & 0 \\
0 & \frac{1}{5}
\end{array}\right]\left[\begin{array}{l}
x \\
y
\end{array}\right]+\left[\begin{array}{c}
\frac{1}{5} \\
\frac{1}{5}
\end{array}\right] \text {, } \\
& W_{4}\left[\begin{array}{l}
x \prime \\
y^{\prime}
\end{array}\right]=\left[\begin{array}{ll}
\frac{1}{5} \cos 45 & -\frac{1}{5} \sin 45 \\
\frac{1}{5} \sin 45 & \frac{1}{5} \cos 45
\end{array}\right]\left[\begin{array}{l}
x \\
y
\end{array}\right]+\left[\begin{array}{l}
\frac{2}{5} \\
\frac{1}{5}
\end{array}\right] \text {, } \\
& W_{5}\left[\begin{array}{l}
x \prime \\
y^{\prime}
\end{array}\right]=\left[\begin{array}{cc}
\frac{1}{5} \cos 45 & \frac{1}{5} \sin 45 \\
-\frac{1}{5} \sin 45 & \frac{1}{5} \cos 45
\end{array}\right]\left[\begin{array}{l}
x \\
y
\end{array}\right]+\left[\begin{array}{c}
\frac{2.5}{5} \\
\frac{1}{5} \sin 45
\end{array}\right] \text {, } \\
& W_{6}\left[\begin{array}{l}
x \prime \\
y^{\prime}
\end{array}\right]=\left[\begin{array}{ll}
\frac{1}{5} & 0 \\
0 & \frac{1}{5}
\end{array}\right]\left[\begin{array}{l}
x \\
y
\end{array}\right]+\left[\begin{array}{l}
\frac{3}{5} \\
\frac{1}{5}
\end{array}\right] \text {, } \\
& W_{8}\left[\begin{array}{l}
x \prime \\
y^{\prime}
\end{array}\right]=\left[\begin{array}{ll}
\frac{1}{5} & 0 \\
0 & \frac{1}{5}
\end{array}\right]\left[\begin{array}{l}
x \\
y
\end{array}\right]+\left[\begin{array}{l}
\frac{4}{5} \\
0
\end{array}\right] \text {, } \\
& W(A)=W_{1}(A) \cup W_{2}(A) \cup W_{3}(A) \cup W_{4}(A) \\
& \cup W_{5}(A) \cup W_{6}(A) \cup W_{7}(A) \cup W_{8}(A),
\end{aligned}
$$

where the generator $W(A)$ is obtained by combining $W_{1}$ to $W_{8}$ which are the set of linear affine transformations and $A$ is the initial geometry. The fractal dimension $D$ for the $1^{\text {st }}$ transformation of the meander-Koch curve Fractal antenna is calculated as 


$$
D=\frac{\log (N)}{\log (r)}=\frac{\log 8}{\log 5}=1.29,
$$

where $N$ is the total number of segments at each iteration and $r$ is number by which the initiator is divided at each iteration.

\subsection{Development of Hybrid Meander-Koch Fractal Ring} Antenna. The proposed antenna in this section has a ring type structure, and it has been formed by following the basis of the fractal geometry. The generator is a meanderKoch curve shape, and the initiator is a trapezoid-like shape with three linear strips that are presented for transformation, as shown in Figure 3(a). The transformation has been carried out in two-steps: in the first step, a meander pattern is applied on each leg of the trapezoid resembling shape. In the next step, the Koch fractal pattern is applied at the top of the meander element, and this is achieved by forming an upper portion of the equilateral triangle in the middle of the meander shape. As a result of this two-step transformation, all the three linear segments have been replaced by the meander-Koch elements, and the obtained shape is illustrated in Figure 3(b). In Figure 3(c), a segment of the microstrip line has been used to interconnect the two arms through the open ends to form a closed loop radiating structure. Practical limitations exist in terms of applying the higher order iterations to design the fractal antennas. These include the overlap between the strips of the adjacent segments in the geometry which consequently deforms its shape. To avoid this situation, the line width should be very narrow; however, this could give rise to the conductor losses which reduces the radiation efficiency. Therefore, the iterative transformation on the meander-Koch Fractal ring antenna has been limited up to the second iteration. Moreover, the dimensions of the proposed meander-Koch fractal ring antenna have been presented in Figure 4 and Table 1.

\section{Parametric Optimization}

After the design of the proposed antenna using IFS, it has been analysed in commercial full-wave simulator CST Microwave Studio (MWS) for studying the effects of the variation of the design parameters. Design goals have been set to achieve an impedance bandwidth that can cover the entire $5 \mathrm{GHz}$ band. In order to realize such an antenna with desired performance, a series of parametric studies have been performed on important design parameters. As elaborated in Section 2.3, the geometric construction of the resultant antenna shape started from an initiator that resembles a trapezoid shape which was presented for transformations using the meander-Koch curve shape. Figure 5 shows the optimization study which has been carried on different lengths of the ringtype antenna. The length $L_{M-k r}$ of the radiating element has been optimized to make the antenna resonant on the entire $5 \mathrm{GHz}$ band.

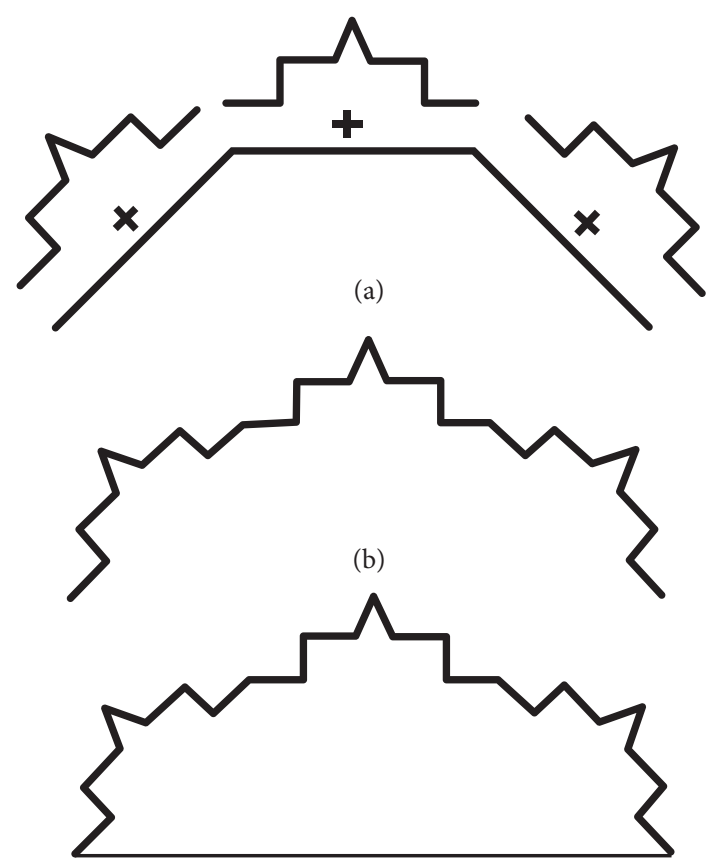

(c)

Figure 3: Transformations of the meander-Koch fractal ring antenna. (a) Geometries of the initiator and generator; (b) combined shape; (c) closed loop.

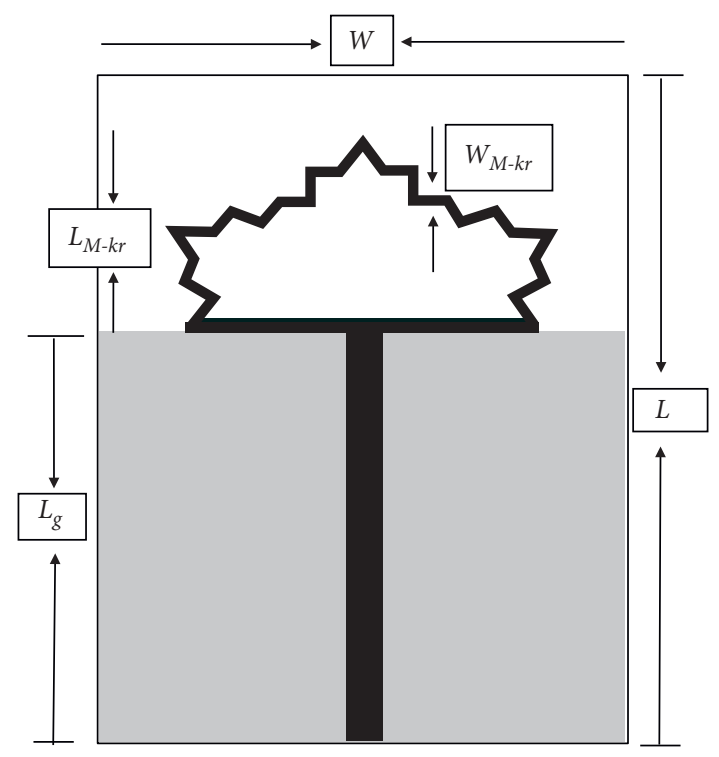

Figure 4: Dimensions of the proposed antenna.

A similar study has been conducted to study the effects of the variation of the fractal ring in Figure 6. The thickness $W_{M-k r}$ of the ring has been varied from $1.1 \mathrm{~mm}$ to $1.3 \mathrm{~mm}$ with a step size of $0.1 \mathrm{~mm}$. It has been noticed that, as the strip thickness increases, the effective perimeter of the ring geometry also increases which results in frequency reduction.

Figure 7 shows the parametric study on the width of the transmission feed line $W_{f}$. It has been optimized to maintain the reflection coefficient at $-10 \mathrm{~dB}$ level for the bandwidth 
TABLE 1: Dimensions of the proposed meander-Koch fractal ring antenna.

\begin{tabular}{lc}
\hline Parameter & Value $(\mathrm{mm})$ \\
\hline$L$ & 45 \\
$W=W_{g}$ & 25 \\
$L_{M-k r}$ & 13.1 \\
$W_{M-k r}$ & 1.1 \\
$L_{f}=L_{g}$ & 26 \\
$W_{f}$ & 1.8 \\
\hline
\end{tabular}

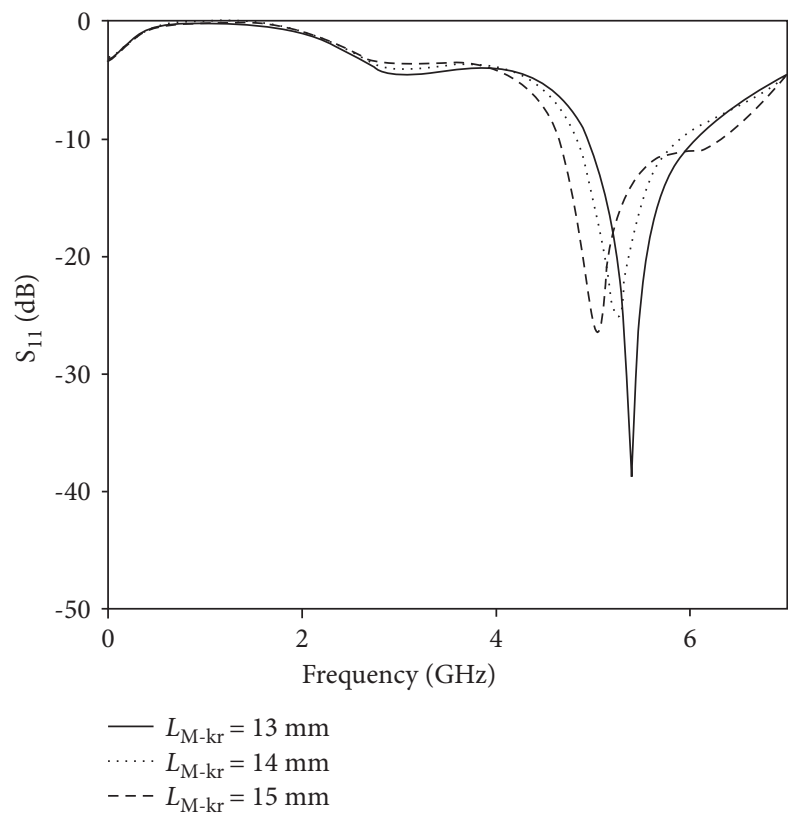

Figure 5: The effect of length of the meander-Koch fractal ring antenna on reflection coefficient.

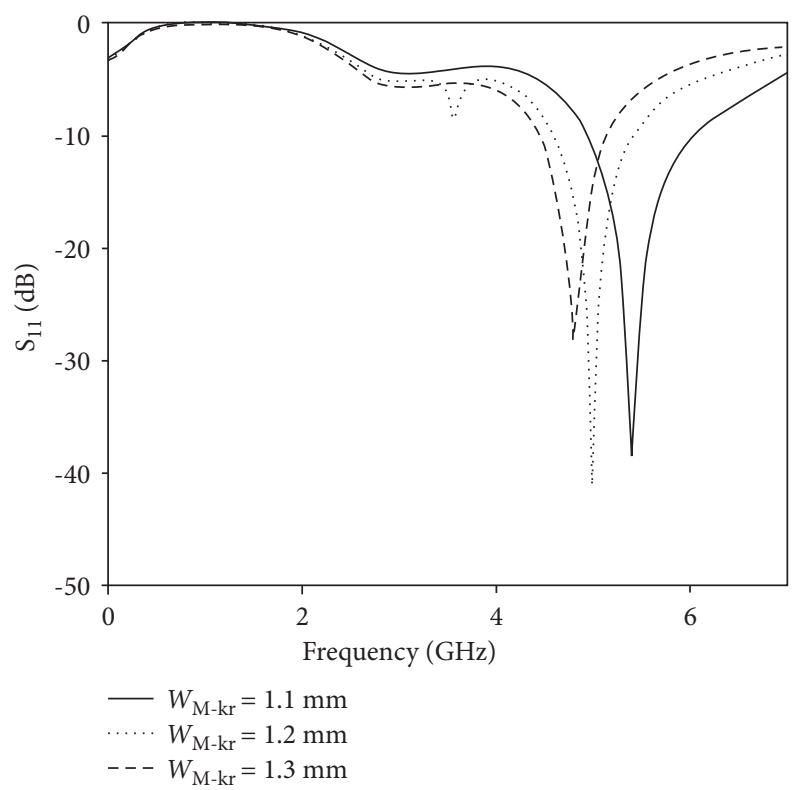

Figure 6: The effect of width of the meander-Koch fractal ring antenna on reflection coefficient.

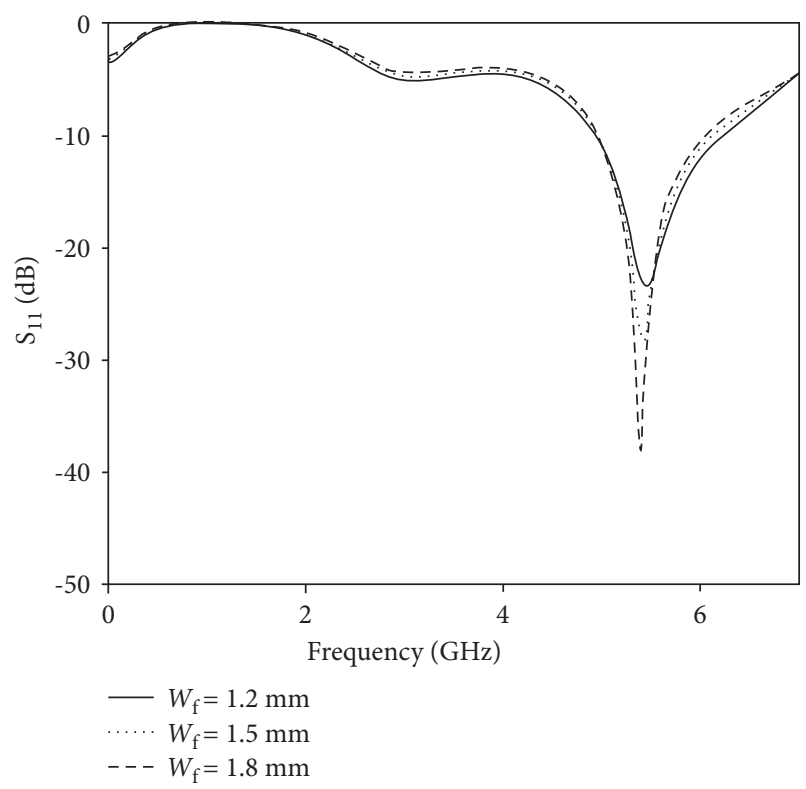

Figure 7: The effect of width of the feed line on reflection coefficient.

covering from $4.94 \mathrm{GHz}$ to $6.12 \mathrm{GHz}$. The width of the transmission line is also a crucial parameter that needs optimization because it is a known reason for impedance mismatch between the antenna and feed line.

The ground plane plays a significant role in the radiation of small antennas. Certain parameters are adversely affected by the small ground plane size. These degradations include a shift in resonant frequencies, impedance mismatch, narrow impedance bandwidth, low gain, low efficiency, and distorted radiation patterns. As illustrated in Figure 8, the final parametric study has been performed by varying the size of the ground plane to avoid the inaccurate measurement results due to cable effects. However, in the optimization process on the size of the ground plane $G$, it was noticed that the width of the ground plane $W_{g}$ has a considerable effect on the resonant frequency and the input impedance, whereas the length has negligible effect on the said parameters. Therefore, for this study the length $\left(L_{g}=26 \mathrm{~mm}\right)$ of the ground plane has been kept constant to perform this study.

\section{Experimental Results}

In Figure 9, the fabricated prototype of the proposed meander-Koch Fractal ring antenna has been presented. It can be noticed from the comparison curves (simulation and measurement), presented in Figure 10, that antenna has satisfactory return loss result. The antenna is designed to operate on the $5 \mathrm{GHz}$ WLAN band. The measured $S_{11}$ plot, as shown in Figure 10, of the proposed antenna shows an impedance bandwidth of $1.18 \mathrm{GHz}$ at $-10 \mathrm{~dB}$ scale.

The simulated and measured far-field radiation patterns of the proposed meander-Koch ring fractal antenna are presented in Figure 11. From the results, the radiation patterns of the meander-Koch fractal ring antenna are 


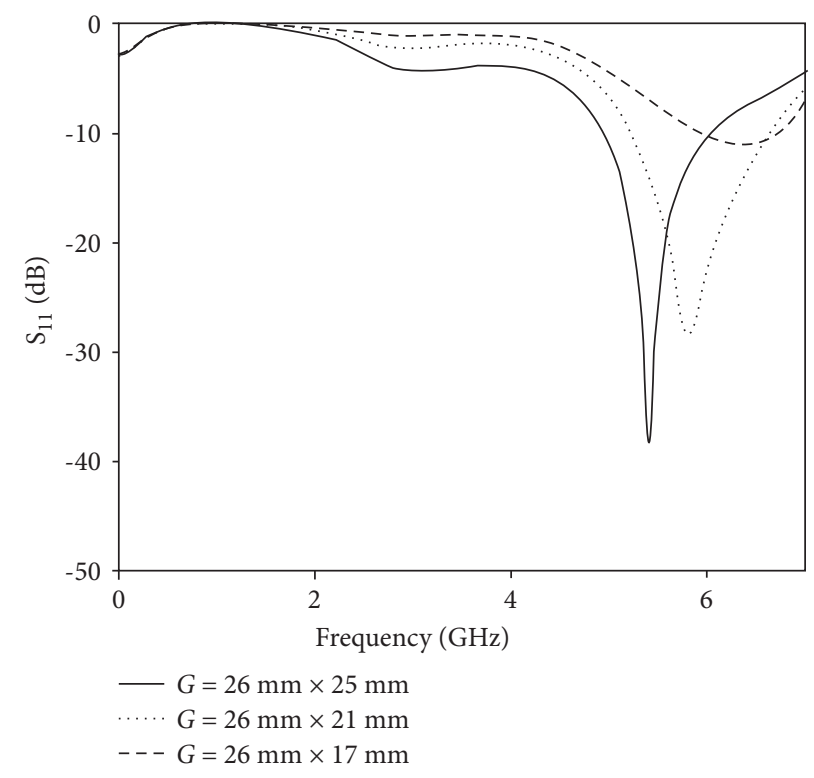

Figure 8: The effect of ground plane size on reflection coefficient.

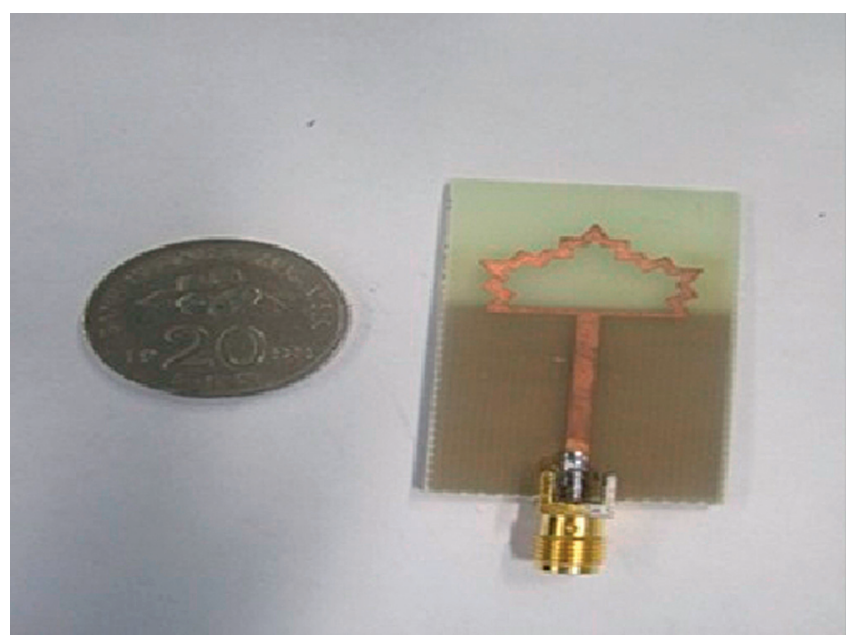

(a)

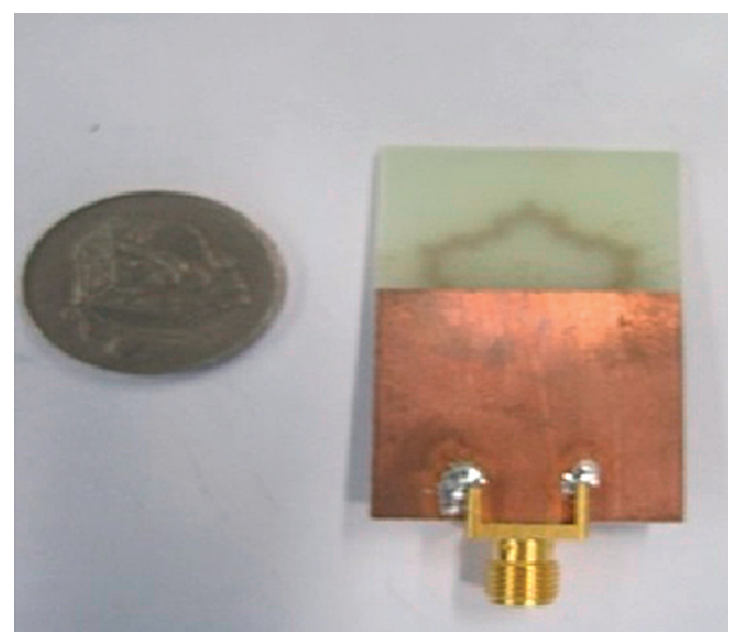

(b)

FIGURE 9: Fabricated prototype of proposed meaner-Koch fractal ring antenna: (a) top view; (b) back view.

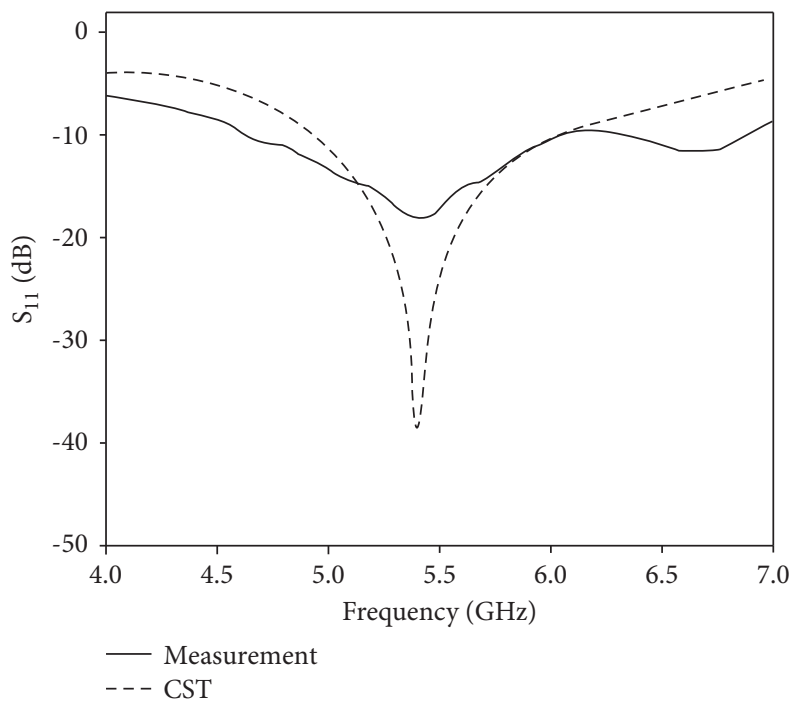

FIGURE 10: Comparison of simulated and measurement results. 


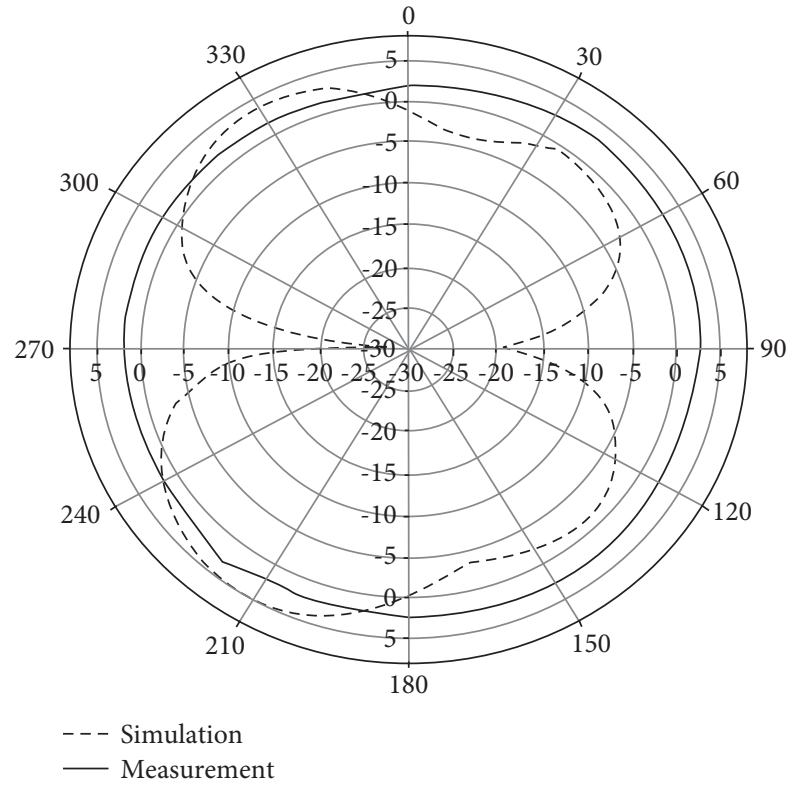

(a)

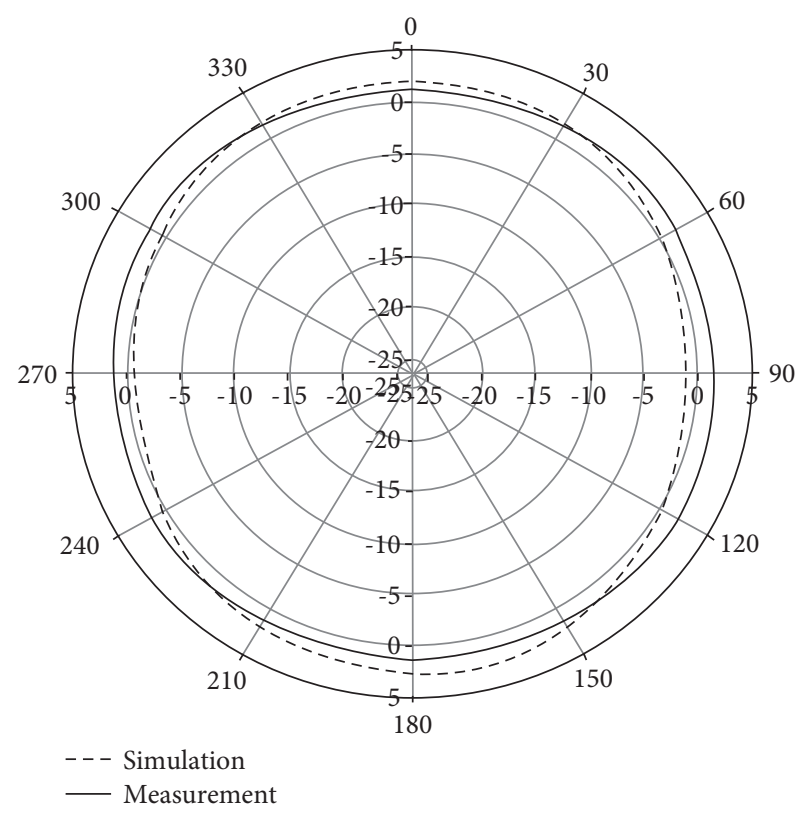

(b)

FIgURE 11: Radiation pattern results of the meander-Koch fractal ring antenna. (a) X-Z plane. (b) Y-Z plane.

omnidirectional, and the antenna has a considerable gain from 0 to $2 \pi$ radians in both the $\mathrm{X}-\mathrm{Z}$ and $\mathrm{Y}-\mathrm{Z}$ planes. Moreover, the measured far-field plot of the proposed antenna in Figure 11(a) illustrates that the proposed meanderKoch fractal ring antenna has symmetric radiation patterns in both the $\mathrm{X}-\mathrm{Z}$ and $\mathrm{Y}-\mathrm{Z}$ planes. Figure 11(a) depicts the simulated $X-Z$ plane radiation patterns for the meanderKoch ring fractal antenna, where it has a maximum gain of $3.5 \mathrm{dBi}$ and doughnut-shaped radiation pattern could be easily noticed. In case of measured results, the maximum gain is $3 \mathrm{dBi}$. Furthermore, Figure 11(b) shows the radiation patterns of the meander-Koch fractal ring antenna in the Y-Z plane. The simulation result shows that the maximum gain is $1.8 \mathrm{dBi}$, whereas the measurement result shows a maximum gain of $1.43 \mathrm{dBi}$.

\section{Conclusion}

In this paper, a hybrid meander-Koch fractal ring antenna has been proposed for $5 \mathrm{GHz}$ WLAN band. The IFS algorithm to construct the generator of the proposed antenna has been compared to the standard Koch curve antenna. Due to an increase in the number of segments of the resulting convoluted shape, the electrical length has been increased, thus miniaturizing the antenna size. Several antenna dimensions have been optimized through the parametric study in CST MWS. The antenna prototype has been realized, and the comparison between the simulated and measurement results has been presented, which confirms the practicality of the proposed antenna.

\section{Data Availability}

No data were used to support this study.

\section{Conflicts of Interest}

All authors declare that they have no conflicts of interest.

\section{Authors' Contributions}

All authors contributed equally in this work.

\section{References}

[1] J. P. Gianvittorio and Y. S. Rahmat, "Fractal antennas: a novel antenna miniaturization technique, and applications," IEEE Antennas and Propagation Magazine, vol. 44, no. 1, pp. 20-36, 2002.

[2] J. Anguera, A. Andújar, J. Jayasinghe et al., "Fractal antennas: an historical perspective," Fractal and Fractional, vol. 4, no. 1, p. 3, 2020.

[3] A. Ramadan, K. Y. Kabalan, A. El-Hajj, S. Khoury, and M. AlHusseini, "A reconfigurable U-Koch microstrip antenna for wireless applications," Progress In Electromagnetics Research, vol. 93, pp. 355-367, 2009.

[4] A. Azari, "A new super wideband fractal microstrip antenna," IEEE Transactions on Antennas and Propagation, vol. 59, no. 5, pp. 1724-1727, 2011.

[5] D. Li and F. Mao, "A Koch-like sided fractal bow-tie dipole antenna," IEEE Transactions on Antennas and Propagation, vol. 60, no. 5, pp. 2242-2251, 2012.

[6] J. Pourahmadazar, C. Ghobadi, and J. Nourinia, "Novel modified pythagorean tree fractal monopole antennas for UWB applications," IEEE Antennas and Wireless Propagation Letters, vol. 10, pp. 484-487, 2011.

[7] M. J. Naghshvarian Jahromi, A. Falahati, and R. M. Edwards, "Bandwidth and impedance-matching enhancement of fractal monopole antennas using compact grounded coplanar waveguide," IEEE Transactions on Antennas and Propagation, vol. 59, no. 7, pp. 2480-2487, 2011. 
[8] S. Dhar, R. Ghatak, B. Gupta, and D. R. Poddar, "A wideband minkowski fractal dielectric resonator antenna," IEEE Transactions on Antennas and Propagation, vol. 61, no. 6, pp. 2895-2903, 2013.

[9] D. V. Kiran, D. Sankaranarayanan, and B. Mukherjee, "Compact embedded dual-element rectangular dielectric resonator antenna combining sierpinski and minkowski fractals," IEEE Transactions on Components, Packaging, and Manufacturing Technology, vol. 7, no. 5, pp. 786-791, 2017.

[10] D. Sankaranarayanan, D. Venkatakiran, and B. Mukherjee, "A novel compact fractal ring based cylindrical dielectric resonator antenna for ultra wideband application," Progress In Electromagnetics Research C, vol. 67, pp. 71-83, 2016.

[11] D. Sankaranarayanan, D. Venkatakiran, and B. Mukherjee, "Koch snowflake dielectric resonator antenna with periodic circular slots for high gain and wideband applications," in Proceedings of the 2016 URSI Asia-Pacific Radio Science Conference (URSI AP-RASC), pp. 1418-1421, Seoul, South Korea, August 2016.

[12] D. Sankaranarayanan, D. V. Kiran, and B. Mukherjee, "Koch snowflake Dielectric Resonator Antenna loaded with a circular metallic patch for wideband applications," in Proceedings of the 2016 URSI Asia-Pacific Radio Science Conference (URSI AP-RASC), pp. 1798-1801, Seoul, South Korea, August 2016.

[13] D. V. Kiran, D. Sankaranarayanan, and B. Mukherjee, "Compact minkowski half-hexagon notched dielectric resonator antenna for wideband applications," in Proceedings of the 2016 URSI Asia-Pacific Radio Science Conference (URSI AP-RASC), pp. 1787-1790, Seoul, South Korea, August 2016.

[14] W. L. Chen, G. M. Wang, and C. X. Zhang, "Small-size microstrip patch antennas combining koch and sierpinski fractal-shapes," IEEE Antennas and Wireless Propagation Letters, vol. 7, pp. 738-741, 2008.

[15] K. C. Hwang, "A modified sierpinski fractal antenna for multiband application," IEEE Antennas and Wireless Propagation Letters, vol. 6, no. 1, pp. 357-360, 2007.

[16] A. Jamil, M. Z. Yusoff, N. Yahya, and M. A. Zakariya, "A compact multiband hybrid meander-Koch Fractal antenna for WLAN USB dongle," in Proceedings of the 2011 IEEE Conference on Open Systems, pp. 290-293, Langkawi, Malaysia, September 2011.

[17] R. A. Kumar, Y. K. Choukiker, and S. K. Behera, "Design of hybrid fractal antenna for UWB application," in Proceedings of the 2012 Int. Conf. Comput. Electron. Electr. Technol. ICCEET 2012, pp. 691-693, Nagercoil, India, March 2012.

[18] N. Sharma, V. Sharma, and S. S. Bhatia, "A novel hybrid fractal antenna for wireless applications," Progress In Electromagnetics Research M, vol. 73, pp. 25-35, 2018.

[19] Y. Kumar and S. Singh, "A compact multiband hybrid fractal antenna for multistandard mobile wireless applications," Wireless Personal Communications, vol. 84, no. 1, pp. 57-67, 2015.

[20] M. Kaur and J. S. Sivia, "Ann and fa based design OF hybrid fractal antenna for ISM band Applications," Progress In Electromagnetics Research C, vol. 98, pp. 127-140, 2020.

[21] I. S. Bangi and J. S. Sivia, "Moore, minkowski and koch curves based hybrid fractal antenna for multiband Applications," Wireless Personal Communications, vol. 108, no. 4, pp. 2435-2448, 2019.

[22] S. S. Sran and J. S. Sivia, "ANN and IFS based wearable hybrid fractal antenna with DGS for S, C and X band application," AEU - International Journal of Electronics and Communications, vol. 127, Article ID 153425, 2020.
[23] R. A. Lituma-Guartan, J. B. Benavides-Aucapifia, D. F. Poveda-Pulla, L. F. Guerrero-Vasquez, and P. A. ChasiPesántez, "A novel hybrid fractal antenna design for ultrawideband application," in Proceedings of the 2018 IEEE 10th Latin-American Conference on Communications (LATINCOM), pp. 1-5, Guadalajara, Mexico, November 2018.

[24] I. S. Bangi and J. S. Sivia, "Minkowski and Hilbert curves based hybrid fractal antenna for wireless applications," AEU International Journal of Electronics and Communications, vol. 85, pp. 159-168, 2018.

[25] S. Rani and A. P. Singh, "A novel design of hybrid fractal antenna using BFO," Journal of Intelligent and Fuzzy Systems, vol. 27, no. 3, pp. 1233-1241, 2014.

[26] S. R. Best, "On the performance of the Koch fractal and other bent wire monopoles as electrically small antennas," in Proceedings of the IEEE Antennas and Propagation Society International Symposium (IEEE Cat. No.02CH37313), pp. 534-537, San Antonio, TX, USA, June 2002.

[27] L. Schulwitz, "The small koch fractal monopole: theory, design and applications," Eng. Comput. Sci. Univ. Michigan, vol. 4, pp. 1-12, 2005, http://scholar.google.com/scholar? $\mathrm{hl}=$ en\&btn $\mathrm{G}=$ Search\&q=intitle:

The+Small+Koch+Fractal+Monopole:

+Theory+design+and+applications\# 1 .

[28] K. J. Vinoy, J. K. Abraham, and V. K. Varadan, "On the relationship between fractal dimension and the performance of multi-resonant dipole antennas using koch curves," IEEE Transactions on Antennas and Propagation, vol. 51, no. 9, pp. 2296-2303, 2003.

[29] C. Puente, J. Romeu, R. Pous, J. Ramis, and A. Hijazo, "Small but long Koch fractal monopole," Electronics Letters, vol. 34, no. 1, pp. 9-10, 1998.

[30] S. Rani and A. P. Singh, "On the design and optimisation of new fractal antenna using PSO," International Journal of Electronics, vol. 100, no. 10, pp. 1383-1397, 2013. 